\title{
Contaminated sites investigation. Objectives and methods
}

Ioan Bica*,

Technical University of Civil Engineering Bucharest, Blv Lacul Tei, no. 122-124, Bucharest 020396, Romania

\begin{abstract}
The past human activities, mainly that related to industrial development caused in many cases a strong contamination of soil, subsoil environment and of groundwater. This type of pollution is a concern because it poses risks to human health and to the ecosystem. More than this, such areas may not be used for new development, requiring solutions for remediation. The management of these sites consists of three main activities: characterization, remediation and, finally, redevelopment. The paper presents a case study dedicated to the first step of contaminated sites management, respectively characterization. This phase is very important, a good characterization could ensure a performant solution for the second step - remediation. Two new techniques for site characterization are presented, as technical principles, but also as performances obtained for the mentioned case study.
\end{abstract}

\section{Introduction}

Industrial activities, municipal and industrial waste disposal, mining activity and other human developments during the past industrial revolution all over the world generated the contamination of soil, subsoil and groundwater. In Europe (EU) there are over 2 million of potential contaminated sites and 150.000 contaminated sites. It is estimated that until 2025 the number of contaminated sites will rise by $50 \%$ [1]. The concern of the management of these areas results from the consequences that pollution puts on the future use of these areas, on one hand and from the risks on human health and the ecosystem as a whole on the other hand.

As it is well known, the main stages of contaminated sites management are (i) characterization of contaminated sites, (ii) remediation and (iii) redevelopment of the area (Fig. 1). The difficulty of remediation of contaminated areas is generated by a series of aspects, which relate to their specificity: (a) accessibility of the underground environment; (b) complexity of the underground environment, formed by the interlocking of three phases: liquid, gaseous, solid; (c) the physical, chemical and biological mechanisms that act on the pollutants reaching in the underground environment [2].

Many useful and innovative technologies for contaminated site characterization and clean-up as well as methods to support decision making processes exist, but they are only rarely applied in their full potential.

\footnotetext{
* Corresponding author: ioan.bica@utcb.ro
} 


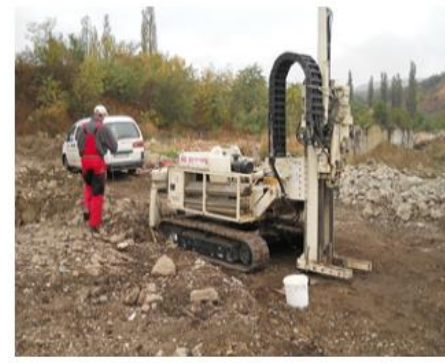

Characterization

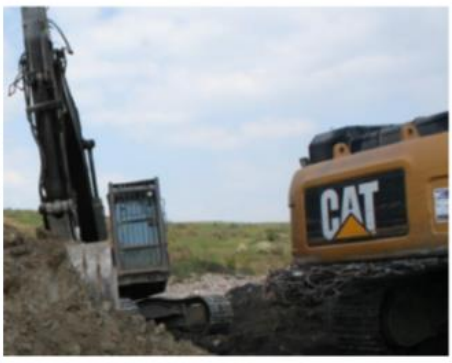

Remediation

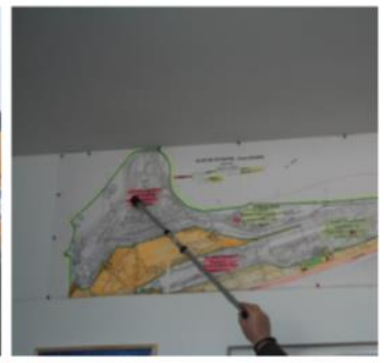

Redevelopment

Figure 1. Stages of contaminated sites management.

Establishing and achieving the remediation levels is a difficult problem because the quality norms specific to the future use of the area, respectively the norms established by the national regulations could be changed in time, on one hand, and on the other hand, the technical performance of the available remediation technologies can't achieve very restrictive goals. The efficiency of remedial technologies is dependent on the difficulties arising from combining the characteristics of the contaminated area (physical, geological, hydrogeological etc.), with the properties of the contaminants (physical, chemical and biological properties).

To achieve decontamination levels based on human health protection is not always feasible - the costs and the time necessary for this goal could be very high. Based on this fact, the future use of contaminated sites must be designed considering the level of remediation that may be achieved in a technical - economical judgment. Or, in other words, the level of remediation could be fixed based on the requirements of a designed activity that has been planned for a specific contaminated site, meaning that it must not be subjected to human health-based criteria on every occasion.

\section{Methods and procedures}

\subsection{Conceptual model}

The analysis of the remediation possibilities will consider the characterization of the area realized by geological, hydrogeological investigations, sampling for analytical determinations, assessing the dynamic of contaminant in the subsurface etc. All these will allow to obtain the necessary information to evaluate the behavior of the contaminant, respectively to evaluate the possibilities of remedying or minimizing the risks posed by the contaminated area. These coherently assembled data help to establish a qualitative and quantitative representation of the characteristics of the area, forming the so-called conceptual model (Fig. 2).

This model must provide the physical characteristics of the area, the type of chemicals founded in the subsurface and their concentrations, and more importantly it must define the main characteristics of water and pollutants motion (Table 1).

The conceptual model provides an image of the structure of the underground environment, its important characteristics for pollutant migration and its behavior, the characteristics of the pollutants found underground and any other aspects that can help to understand the temporal and spatial evolution of the pollutant front and the risks that it puts on the receivers. 


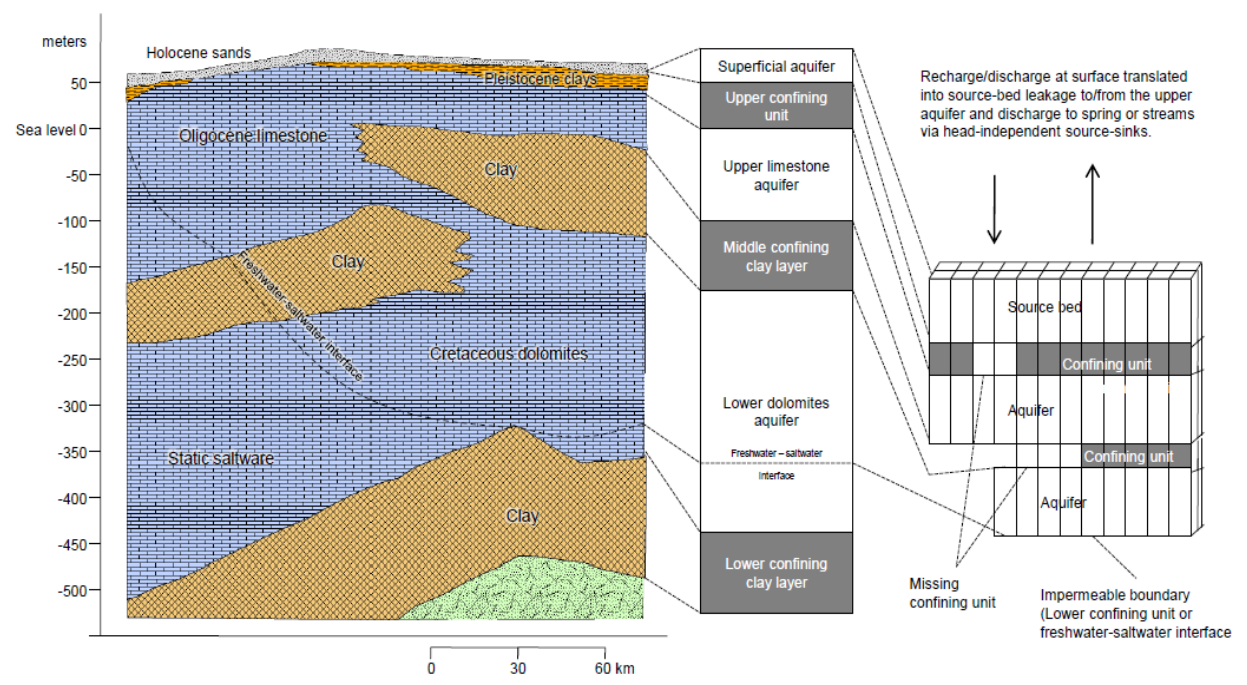

Figure 2. The construction of the conceptual model [3].

The conceptual model offers a three-dimensional image of the conditions of a contaminated site, illustrating the distribution, the mechanisms of contamination behavior, the routes of exposure, the migration routes, and the potential specific receptors [9].

Table 1. Type of data for Conceptual model [2]

\begin{tabular}{|c|l|l|}
\hline $\mathbf{1}$ & General information & $\begin{array}{l}\text { Wells position, type of groundwater bodies, environmental } \\
\text { receptors position }\end{array}$ \\
\hline $\mathbf{2}$ & $\begin{array}{l}\text { Geology and } \\
\text { hydrogeology }\end{array}$ & $\begin{array}{l}\text { Local and regional geology, physical properties, } \\
\text { stratigraphy, groundwater level, hydraulic conductivity, } \\
\text { isotropy, porosity, groundwater recharge/discharge, etc. }\end{array}$ \\
\hline $\mathbf{3}$ & Contamination source & $\begin{array}{l}\text { Position and history of the contamination source } \\
\text { activities). Position of underground contamination } \\
\text { sources. }\end{array}$ \\
\hline $\mathbf{4}$ & $\begin{array}{l}\text { Contamination } \\
\text { distribution and } \\
\text { transport }\end{array}$ & $\begin{array}{l}\text { Underground spatial distribution of contaminants, } \\
\text { contamination mass, contamination processes and } \\
\text { transport, geochemical properties of the rocks, etc. }\end{array}$ \\
\hline
\end{tabular}

The conceptual model is a dynamic, flexible working tool that will be improved as new characterization data for the contaminated area are available. The conceptual model will be validated by simulating, with the help of mathematical models, the processes carried out underground. The calibration of the mathematical model on situations determined by in situ measurements offers arguments in accepting its conformity with the real situation.

\subsection{Investigation of contaminated sites}

The methods of investigating the subsurface environment have developed over time and have reached significant performances. However, the investigation of the contaminated subsurface environment is a relatively new activity and imposes procedures, criteria, and objectives different from the investigation carried out for other purposes. As a result, its transposition to the contaminated environment without adjustment and adaptation to its specifics can lead 
to disturbance of the subsurface environment, to the further complications of the behavior of the pollutant in the subsurface, respectively difficulties in applying the remediation solution.

The establishment of the investigation method, appropriate to a site, is done by quantifying the advantages and limitations dictated by the specificity of the investigated site as well as by the type of data required for its optimal characterization. In principle, the data obtained should ensure an adequate risk assessment, in order to allow the identification and establishment of the potential and the optimal solution for remediation (Fig. 3).

Attempting to achieve perfection in characterizing the contaminated area can be detrimental because performing too many drills for sampling will disrupt the structure of the natural environment, thus causing changes in the behavior of pollutants in this area. In these conditions, the studies of the characterization of the polluted area must strike a balance between the desire to obtain all the information necessary to design an efficient remediation system and the need to avoid the wide disturbance of the subsurface environment through the characterization investigations [2].

From those multitude site investigation methods, only two were used for this study, Direct Push and Phytoscreening.

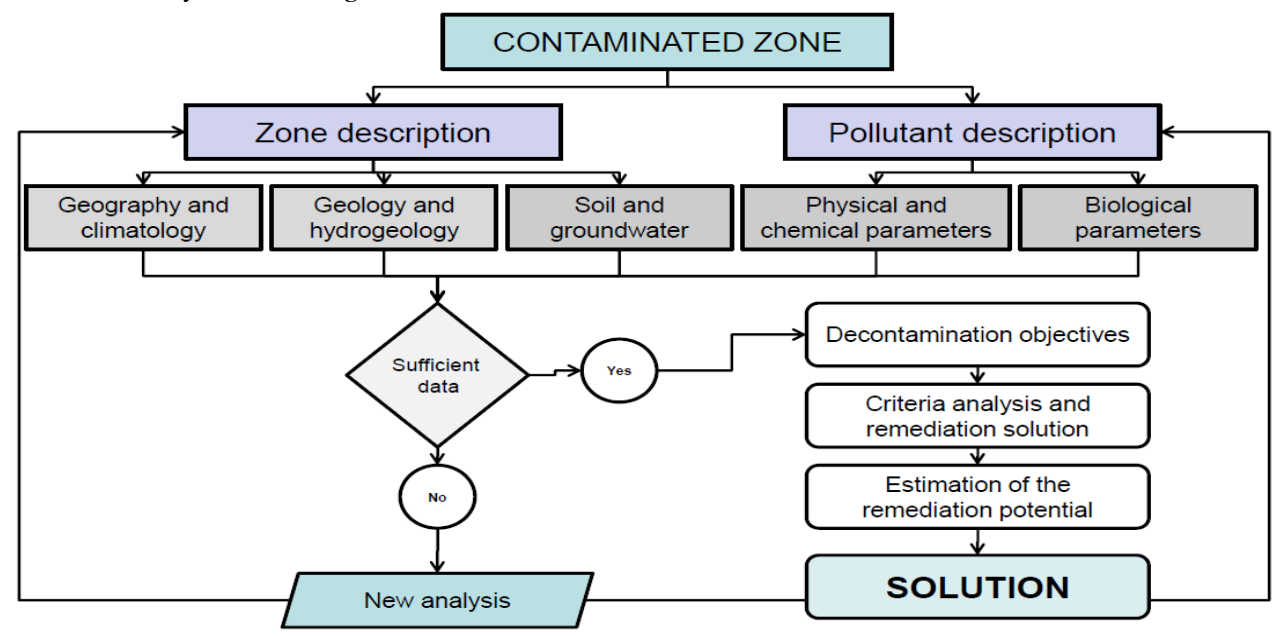

Figure 3. Flow chart of the contaminated zone characterization.

\subsubsection{Direct Push}

Direct Push [2,3] is a hydraulic-powered subsurface investigation method where both static force and percussion are used to advance sampling and logging tools into the subsurface. No rotation is needed to advance and there is no drilling debris on the surface (Fig. 4).

DP-techniques are multifunctional investigation methods able to provide a detailed characterization of the underground. The DP-based techniques can be applied in the unsaturated/saturated zone and are especially efficient in unconsolidated clayey, sandy and gravely deposits. They offer the possibility of continuously recording investigation relevant parameter, sampling of the soil, soil gas and groundwater and installing monitoring wells.

One important role in the spatial distribution of the contaminants is played by the hydrostratigraphic features of the site. Retrieving valuable information about the subsurface can be done in real-time using DP-methods through different specialized sensors [3]. 


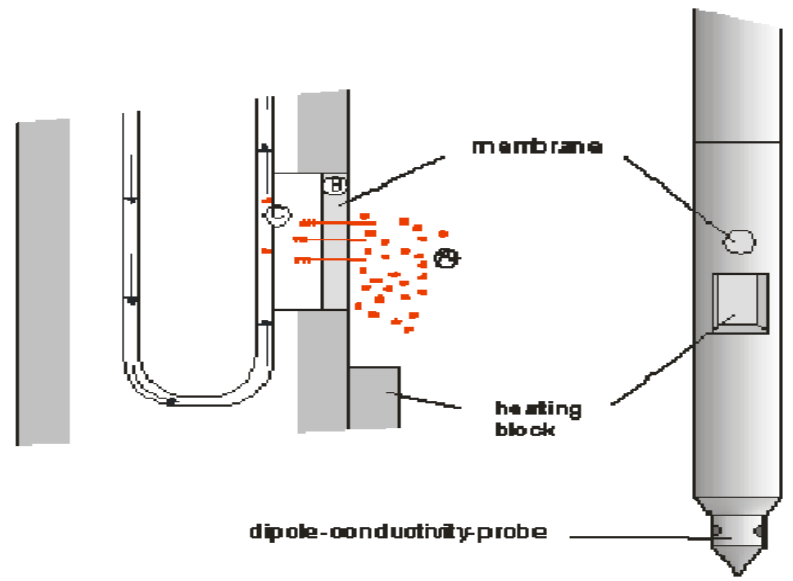

Figure 4. Direct Push method

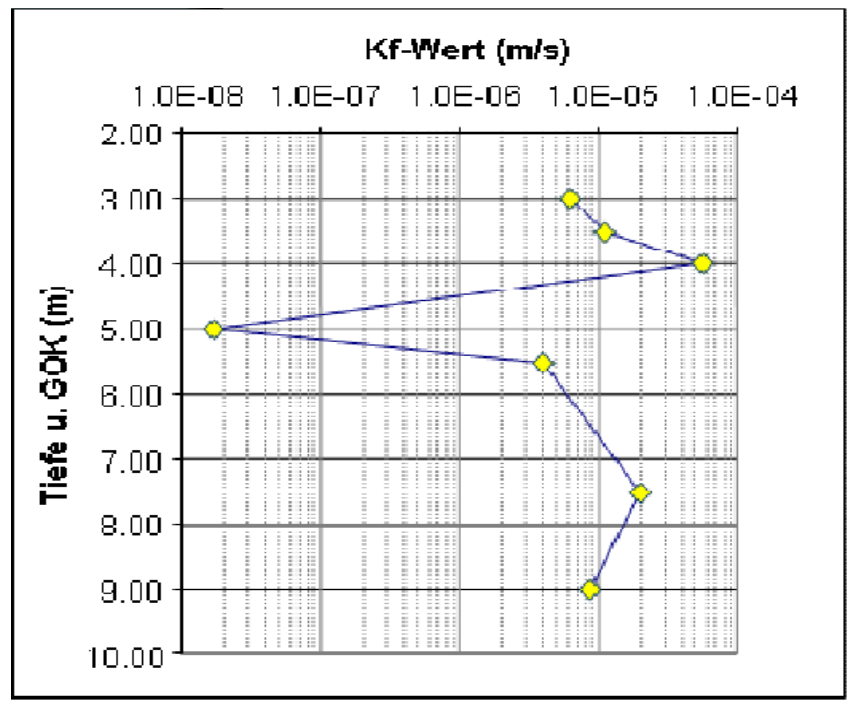

Figure 5. The result of hydraulic conductivity test

The Electrical conductivity (EC) profiling method provides on-site, through a direct measure of the electrical conductivity of the underground, an indirect information of the subsurface lithological characteristics. The EC technique is an excellent tool for rapid delineation of the underground heterogeneity. Through this method, vertical profiles of the electrical conductivity are derived in order to map thin layers [3].

In situ testing of hydraulic conductivity can be performed by injecting water under a specified pressure (4-5 bar) into the aquifer. The water flows into the layers in an easier or heavier way, depending on the hydraulic properties of the medium. The interpretation provides in a preliminary stage a relative profile of hydraulic conductivity. By means of several slug tests, the results are site-specific and translated into absolute values of hydraulic conductivity (Fig. 5.).

Online profiling of contaminant distribution (MIP) - Membrane Interface Probe is a rapid screening tool for locating volatile organic compounds in the subsurface. MIP is a powerful logging device able to detect volatile organic compounds and record semiquantitative data in a continuous depth profile. MIP collects real-time, vertically continuous data on the 
distribution of VOCs as well as an electrical conductance (EC) log that is indicative of the crossed lithology.

The in-situ chemical instrumentation is based on a probe that is connected to laboratory instrumentation by a capillary tube system and control cable. The online analysis takes place using a MIP-System connected to a gas chromatograph - GC. The combination of three GC detectors allows distinguishing between different types of VOC's.

Discrete groundwater sampling - The groundwater sampler has a $36 \mathrm{~mm}$ outer diameter (OD) and will be driven to the sampling depth. When probes are placed at desired sampling depth, a stainless-steel filter will be exposed by retracting the sheath. The groundwater that flows through the filter is pumped according to low-flow method procedures. Low-flow methods minimize the volatilization of VOC's. The field parameter (ORP, O2, pH, temperature, and electrical conductivity) are measured on site by using a flow-through cell.

\subsubsection{Phytoscreening with tree cores}

The sampling of plants represents an economical and non-invasive method that complements conventional methods of investigating pollutants in the groundwater and soil (leachate) [3]. The fundamental principle thereby is that the solved contaminants are absorbed through water by the roots. Inside the plant the substances move upwards with the sap current into the trunk or stem and then into the leaves [3,4].

Tree coring is a semi-quantitative screening tool which can be applied initially for location and mapping of pollution. The method is well suited for large sites and to locate (single) hot spots. However, the results should be confirmed by quantitative screening methods such as groundwater sampling or soil sampling $[4,5]$.

Using an increment borer (Fig. 6), tree cores can then be taken from the trunks of trees and analyzed in the laboratory for pollutants. The measured contents can then provide us with insights into the subsurface contamination of a particular site. The scientific literature refers to this semi-quantitative procedure as phytoscreening. The suitability of phytoscreening for investigation or monitoring purposes could already be undoubtedly proven for some pollutants, particularly those in the group of chlorinated solvents.
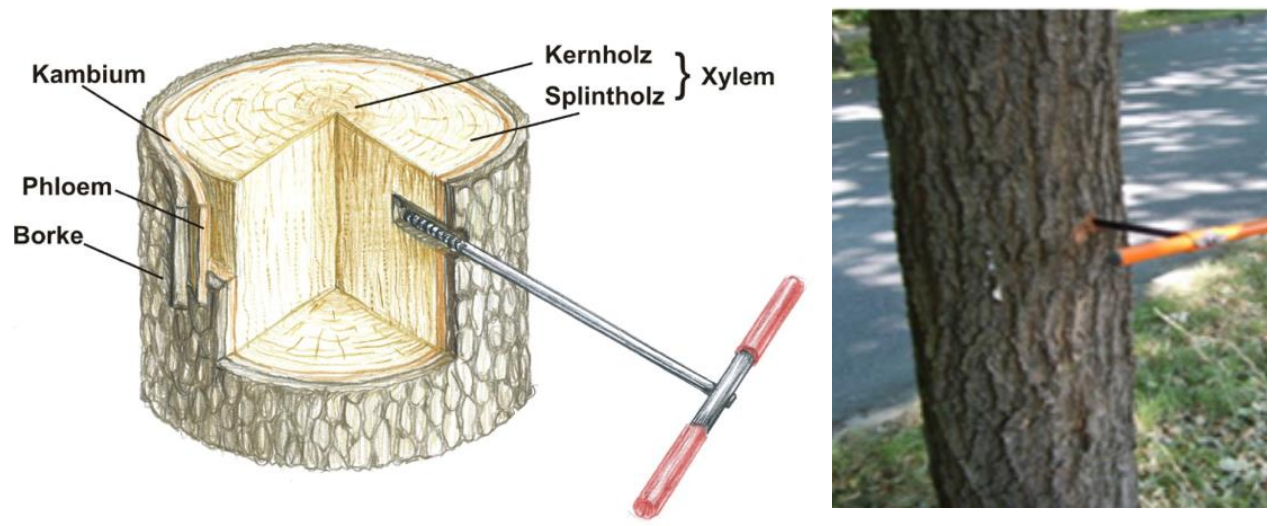

Figure 6. Phytoscreening with tree cores.

The method is recommended by its many advantages [5]: fast, easy, and only little effort is needed to screen a large test site; cheaper than others; suitable at sites where application of conventional site characterization methods is limited/problematic due to the sensitivity of a site; certain site features (moor, rocks, forest), location of the site (inner cities, risk of pipes 
or cables) or due to former/current activities at the site; minimal impact on the site and the environment; allows a fast overview of the spreading of the pollutants and can this way serve as initial screening method; root systems can be larger than the crown of the tree [6].

\section{Case study. Investigations and results}

The case study refers to a former industrial activity, dating back to 1884, with alternating stops and re-commissioning, and periods of development or activity restraints. The integrated steel mill included tall furnaces, coke ovens, classic ovens, electric ovens for sheets, wires or steel profiles. Part of the chemical-coke sector was located in the West side, a storage area of the resulted tar from this section being identified. Starting with 1999, no more steel activities were performed, but only demolishing processes.

From the lithologic point of view, the area is characterized by the presence of gravel until $10 \mathrm{~m}$ depth, covering a carbonate (karstic) environment. The main aquifer is represented by a karstic groundwater body located under the gravel layer. The groundwater table of the superficial aquifer is located at about $5 \mathrm{~m}$ depth.

The 51 percussion holes drilled down up to $2 \mathrm{~m}$ depth served for a good geotechnical description of subsurface and for reliable soil gas measurements as well as for the investigation of heavy metals presence and distribution in top soil $(0-20 \mathrm{~cm})$ and in depth $(1-$ $2 \mathrm{~m})$. High concentrations of ionizable gas were measured in vicinity of remnants of tanks. Generally low soil gas values were detected throughout rest of area. Higher values of heavy metals were measured throughout the investigated area $(\mathrm{Zn}, \mathrm{As}, \mathrm{Cu}, \mathrm{Ni}, \mathrm{Pb}, \mathrm{Cd}$ ) but vertically limited mostly to topsoil $(0-20 \mathrm{~cm})$. In depth $(1-2 \mathrm{~m})$ generally low values are present [8].

By the aid of DP-techniques (Fig.7), the following have been obtained: derived aquifer geometry (bottom, top and thickness), hydraulic properties distribution maps (based on lithological information, (Fig. 8) and grain size distribution values on 18 samples, hydrogeological map (groundwater level) - based on groundwater and surface water measurements. All these were after that used for the configuration of conceptual model of the area $[3,8]$.

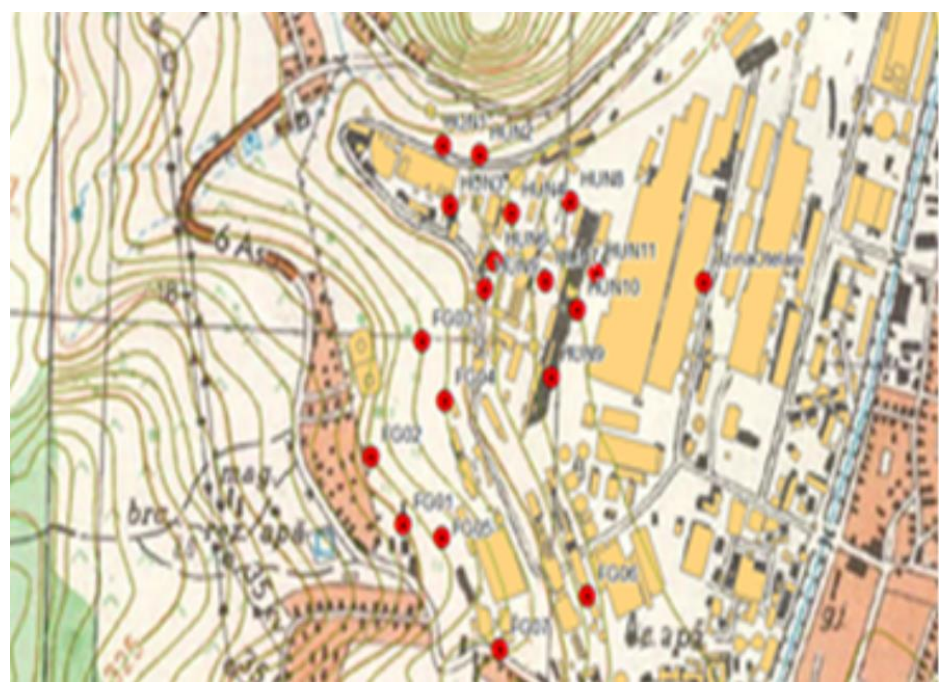

Figure 7. DP investigation boreholes location. 


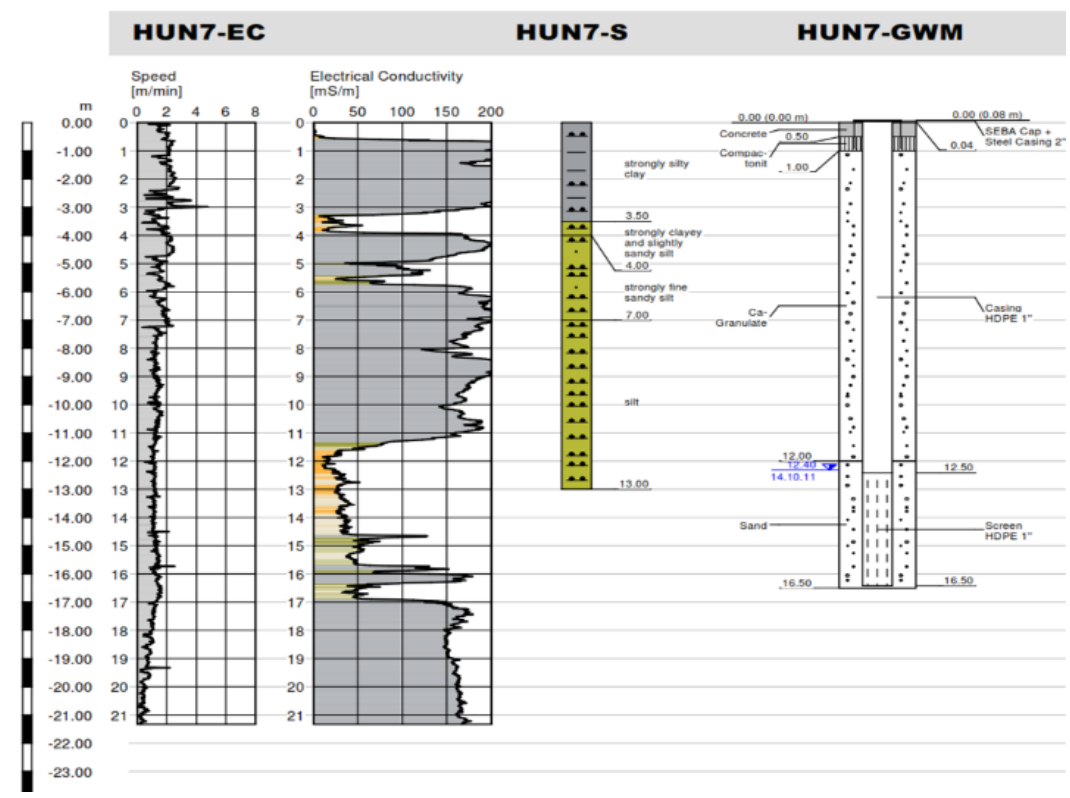

Figure 8. Typical hydrogeological features

Based on same technology, 3D representation of the structures of the geology is obtained. It is useful for understanding the stratigraphy, the potential continuity of the layers and the contaminants' behavior (Fig. 9). The soil samples allow the representation of the distribution of the contaminants in subsurface zone (Fig. 10).

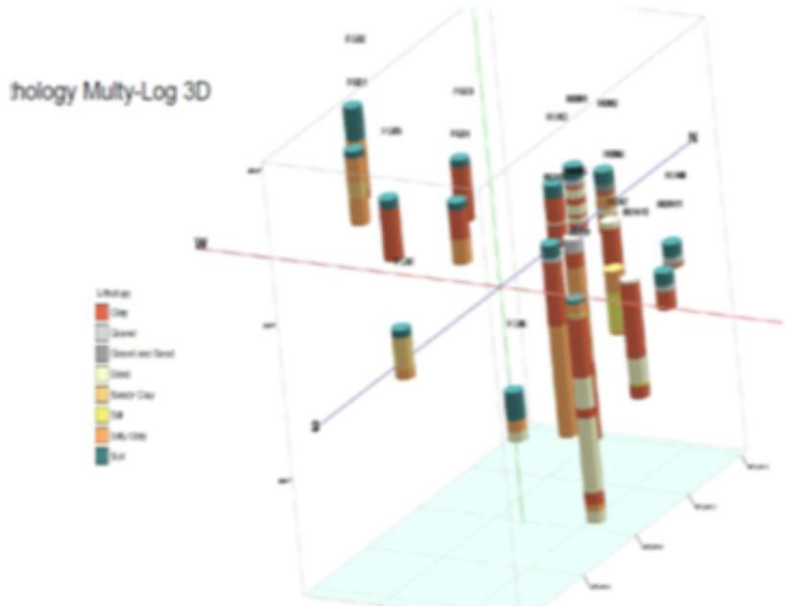

Figure 9. Spatial representation of geology 


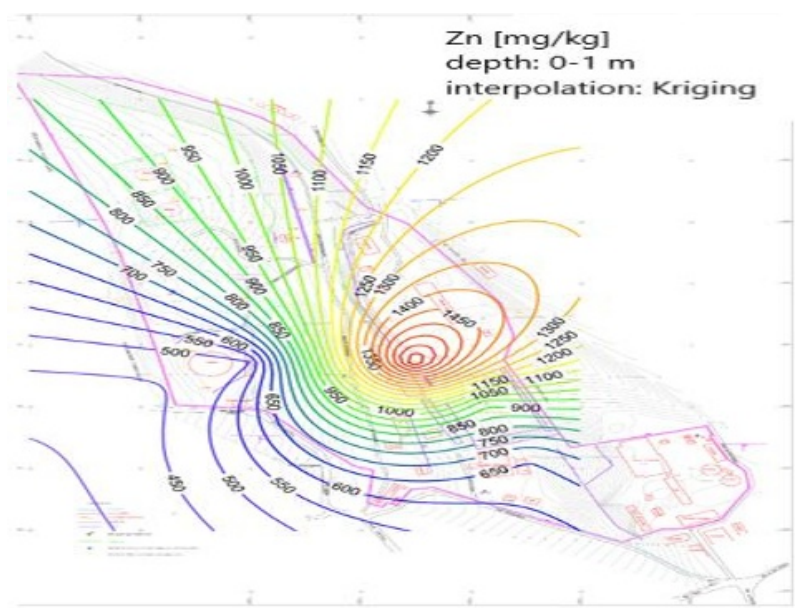

Figure 10. Spatial distribution of contaminant: $\mathrm{Zn}$.

The major contamination issue for the area are the heavy metals [8]. Also, other contaminants can be found in the soil and in the groundwater in significant concentrations, as for example naphthalene, toluene, benzene (Table 2).

Table 2. Vertical distribution of main contaminants $(\mathrm{mg} / \mathrm{kg})$ [3]

\begin{tabular}{|c|c|c|c|c|c|}
\hline Depth (m) & Oil products & Arsenic & Lead & Toluene & Benzene \\
\hline 2.8 & 970 & 7.62 & 16.00 & 0.09 & 0.23 \\
\hline 4.8 & 2048 & 4.00 & 10.30 & 5.36 & 12.90 \\
\hline 7.5 & 903 & 4.00 & 7.80 & 0.23 & 0.76 \\
\hline 9.2 & 3923 & 10.70 & 15.20 & 1.53 & 7.23 \\
\hline 11.5 & 3061 & 4.00 & 6.59 & 0.54 & 0.49 \\
\hline 12.8 & 727 & 7.12 & 9.17 & 0.75 & 2.72 \\
\hline 14.7 & 1629 & 10.90 & 6.81 & 1.83 & 11.00 \\
\hline
\end{tabular}

Table 2 shows a high distribution of contaminants in depth. This could be explained by lithological affinities (organic compounds - benzene, toluene - hydrophobic accumulation in pelitic rocks). Metals (lead) very immobile. Once introduced in the soil matrix $\mathrm{Pb}$ is very difficult to remove. However, this industrial platform, during its 100 years of operation, was the subject of many reconstructions, excavation and earth fillings and mixing it from different levels; sometimes excavations for deep foundations etc.

The tree coring method was tested as a bioindicator for both heavy metals and BTEXN compounds. The sampling for heavy metals was done without knowing much about the heavy metal level at the site beforehand. The samples were therefore collected all over the site and allocated to subareas (Fig. 11). The average concentrations of each subarea are shown in Fig.12. Most of the average concentrations of the test site are above the average concentrations of the reference samples $[5,8]$.

For BTEXN compounds, tree coring as a phytoscreening method was tested in the initial phase in order to answer the question if the compound can be detected or not in wood. BTEXN compounds have been detected in 4 out of 21 samples, all in the high-risk area. For benzene, even different levels were observed. This indicates that the trees can take up BTEXN compounds from the subsurface and transport them to the stem [4.5]. 


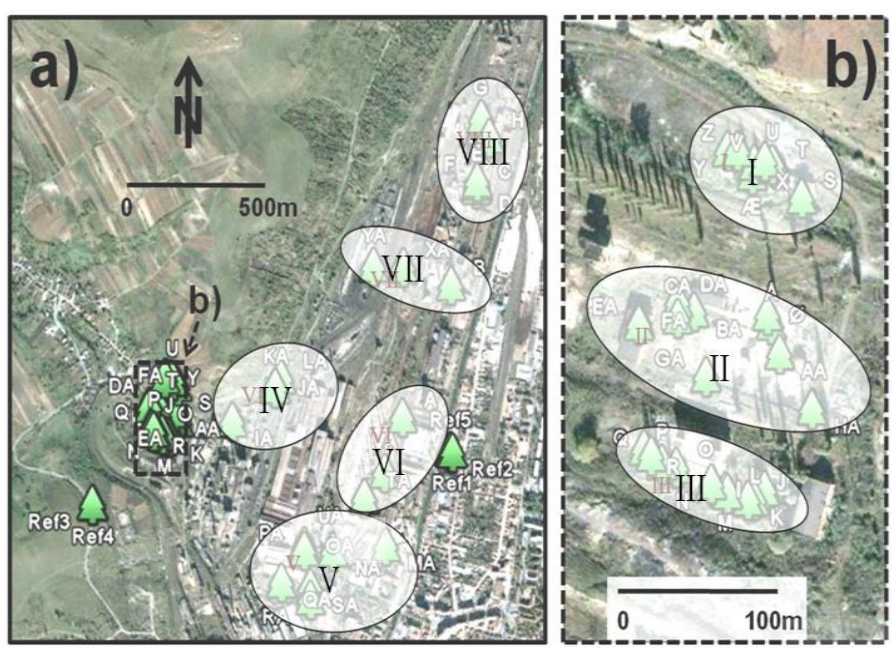

Figure 11. Map of the test site showing the subareas used to evaluate the pollution of heavy metals. b) is a zoom into a).

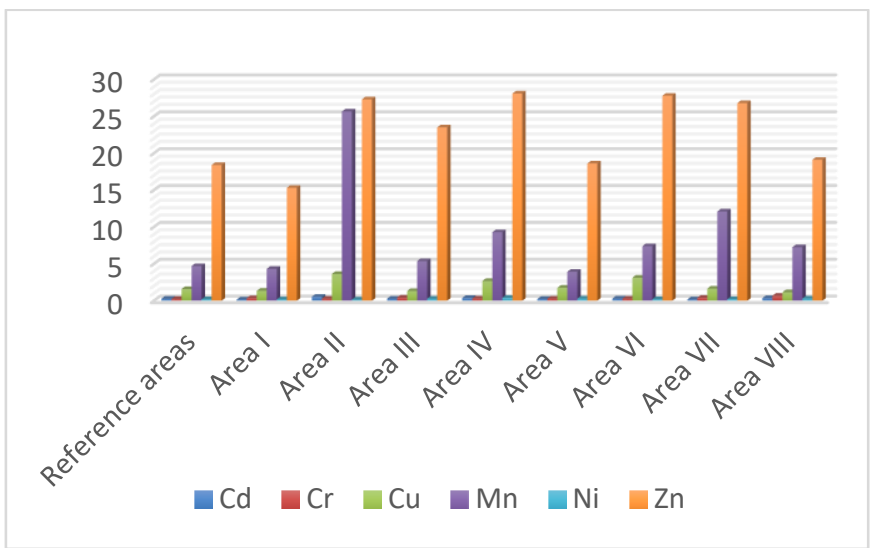

Figure 12. Average concentrations measured in the trees from each subarea.

\section{Conclusions}

Characterization of contaminated sites is one of the most difficult activities, because the local data must be extrapolated to have a clear image of the whole subsurface area. The conceptual model can be used to have a picture of the subsurface area, and to understand its behavior. It can also be used in modeling the trend of contaminated plume and to test the efficiency of different remediation solutions. Nondestructive (noninvasive) methods of investigation are preferred because they do not disturb the underground zone, but they can fail to provide very accurate data. DP technology and phytoscreening are one the best novel methods for this purpose.

Based on the results of this investigation, the main conclusion is that the redevelopment of the platform area could be divided in three sectors: first one will be used for light industrial activities, the second one is proposed for recreation (vegetation and forests plantation, where phytoremediation may be activated), and last one could be used for residential development (after using soil washing as remediation solution).

The author acknowledges the BRIGAID EU project for technical, scientific, and financial support. 


\section{References}

1. EEA, The European Environment. State and outlook. (European Environmental Agency, Copenhagen, 2005)

2. I. Bica. Remediation of contaminated sites. (Orizonturi Universitare, Timisoara, 2014)

3. I. Bica, D., Gaitanaru, Solving Environmental Problems Through the Understanding of Risk and Environmental Processes: International Workshop (Institute of International Health, Michigan State University, Technical University of Civil Engineering, Bucharest, 2014)

4. M. Algreen, Guideline for application of Tree Coring as an initial screening tool for typical pollutants in the subsurface, (2013)

5. M. Algreen, St., Trapp, Guideline for application of Tree Coring as an initial screening tool for typical pollutants in the subsurface (TIMBRE, 2014)

6. M.C. Dobson, A.J. Moffat. Waste Manag. and Res., 13, 579-600 (1995)

7. N. Fatin-Rouge, Feasibility of specific soil washing with recycled solutions (SSWRS) for the removal of selected metals and organic compounds from contaminated soil and mathematical model to assess pollutant transfer by SSWRS (TIMBRE, 2013)

8. E. Martac, Comparative study of site investigation approaches and potential in situ remediation techniques: model-assisted evaluation of advantages and uncertainties (TIMBRE, 2014)

9. US-Environmental Protection Agency, Innovative Treatment Technologies: Annual Status Report (Eighth Edition), 542-R96-010 (EPA, 1996) 